Article

\title{
Streamer Propagation and Breakdown in a Very Small Point-Insulating Plate Gap in Mineral Oil and Ester Liquids at Positive Lightning Impulse Voltage
}

\section{Pawel Rozga}

Institute of Electrical Power Engineering, Lodz University of Technology, Stefanowskiego 18/22, 90-924 Lodz, Poland; pawel.rozga@p.lodz.pl; Tel.: +48-42-631-2676

Academic Editor: Issouf Fofana

Received: 4 May 2016; Accepted: 7 June 2016; Published: 17 June 2016

\begin{abstract}
This article presents the results of comparative studies on streamer propagation and breakdown in a point-insulating plate electrode system in mineral oil and two ester liquids. The studies were performed for a 10-mm gap and a positive standard lightning impulse. The work was focused on the comparison of light waveforms registered using the photomultiplier technique. The results indicated that both esters demonstrate a lower resistance against the appearance of fast energetic streamers than mineral oil. The reason for such a conclusion is that the number of lightning impulses supplied to the electrode system for which the above-mentioned fast streamers appeared at a given voltage level was always higher in the case of ester liquids than mineral oil. In terms of breakdown, the esters tested were assessed as more susceptible to the appearance of breakdown in the investigated electrode system. The number of breakdowns recorded in the case of esters was always greater than the corresponding number of breakdowns in mineral oil. This may be supposed on the basis of the obtained results that imply that, in both synthetic and natural ester, the formed breakdown channel, which bridged the gap through the surface of pressboard plate, is characterized by higher energy than in the case of mineral oil.
\end{abstract}

Keywords: streamer propagation; mineral oil; synthetic ester; natural ester; lightning impulse; breakdown

\section{Introduction}

Synthetic and natural esters as alternative liquids for mineral oils have become more and more popular in transformer applications. This is primarily due to the fact that mineral oils, commonly used as insulating and cooling medium in transformers, are not neutral to the environment and may constitute a potential threat to the soil and watercourses when they release into the environment. The synthetic and natural esters, from the point of view of environmental hazards, are friendlier to the environment because of their better properties connected with biodegradability and flammability. In comparison to the mineral oils, esters are characterized by biodegradability of about $90 \%$ compared to only $10 \%$ characteristic of mineral oils, with a fire point (above $300^{\circ} \mathrm{C}$ ) higher than mineral oils, which provides their fire-resistant nature [1-7].

Both esters, apart from having environmentally friendly properties, should fulfill some requirements concerning their dielectric characteristics. In terms of electrical strength at AC voltage, synthetic and natural esters are more resistant to the influence of moisture content on this electrical strength. For example, for synthetic ester, even up to $600 \mathrm{ppm}$ of moisture content, its AC breakdown voltage does not change, while for mineral oils a small amount of water in the oil volume (circa 20-30 ppm) decreases AC breakdown voltage significantly. Besides, both esters are characterized by the ability to absorb water from the insulating paper, which is desirable from the point of view of paper 
aging. Additionally, higher electrical permittivity of esters (3.2-3.3) compared with that of mineral oils (2.2-2.4) results in a more uniform electrical field distribution in a paper-dielectric liquid insulating system $[4,5,8-12]$.

Despite many positive features of the esters, the studies concerning streamer propagation and breakdown under lightning impulse (LI) voltage have indicated that esters may behave worse than mineral oils at such types of voltage stresses [13-17]. Because the number of the studies in this field is still limited, and knowledge is still regarded as insufficient to clearly determine which of the liquids (esters or mineral oils) behave better under LI stresses and why, the authors' studies have only been focused on the above-mentioned aspect and are presented in this paper in terms of a very short $(10 \mathrm{~mm})$ point-plate gap. The studies have been focused on a positive polarity due to a well-known fact that this polarity is more dangerous for the real insulating systems with solid components. In contrast to the majority of published works [13-16,18-21], the author used an insulating plate placed on the grounded electrode. This allowed for closer alignment of the electrode system tested with real systems, where the inhomogeneity caused by the point electrode may constitute a place of locally increased intensity of the electric field stress and where the discharge develops only from this point to the electrode, which is usually insulated $[17,22,23]$.

The commonly adopted approach in the assessment of esters is based on the comparison of ester features with features of mineral oil registered in the same testing conditions [2-4,8-11,13-17]. Among the features of the streamers developing in dielectric liquids, the most important are the streamer shapes, currents, and light waveforms, as well as propagation velocity. All of these indicators change with the so-called propagation modes which occur together consecutively with voltage increases in the given electrode configuration. In view of the propagation velocity of the streamers, these modes are divided into slow and fast. However, within these main modes, there are some sub-modes, such as 1st and 2nd mode (characterized by propagation velocity of a few $\mathrm{mm} / \mu \mathrm{s}$, commonly referred to as slow) and 3rd and 4th mode (having propagation velocity from a dozen to tens of $\mathrm{mm} / \mu \mathrm{s}$, commonly referred to as fast) [18-21]. Recognition between distinctive modes may be also identified on the basis of light and current characteristics, where the differences between the modes are clearly visible. Generally, it is a well-known fact that the 1st and 2nd propagation modes concern the streamers of relative low energies, while 3rd and 4th modes concern higher energies. Which propagation mode occurs depends on the value of testing voltage and thus on the value of the local electrical field, also resulting from the geometry of the electrode system. This may be said that lower values of electrical field stress (from tenths of $\mathrm{MV} / \mathrm{cm}$ to few $\mathrm{MV} / \mathrm{cm}$ ) cause the development of slow propagating streamers, while higher values of electrical field stress (from tens to even $100 \mathrm{MV} / \mathrm{cm}$ ) may contribute to the propagation of the fast, high-energy streamers. However, the moment of the appearance of fast streamers with an increase of testing voltage is also connected with the type of liquid in which the streamers develop. Ionization and excitation of the molecules in the given liquids are the molecular structure-dependent processes [13-22].

In the comparative assessment of the liquid behavior at lightning impulse stress, an especially important aspect is the determination of the value of voltage, at which a change in propagation mode from slow to fast occurs. This value has been called the acceleration voltage (and marked commonly as $V_{\mathrm{a}}$ ) and has been related to the value of inception or breakdown voltage for a given electrode setup. The accepted name "acceleration voltage" comes from the fact that the streamers rapidly change their propagation velocity from a few to tens of $\mathrm{mm} / \mu$ s after exceeding this value of voltage. As mentioned above, the change of propagation velocity entails the change of the spatial shape of the streamers and the recorded time-dependent courses of current and light. Simultaneously, this change is accompanied by a higher energy of the streamer channels. If breakdown takes place within the development of fast streamers, the energy of the breakdown channel is also much higher than the corresponding energy of the breakdown channel being a result of development of slow propagating streamers. Thus, the observation of pre-breakdown and breakdown phenomena for different dielectric 
liquids in the same testing conditions may allow for the assessment of the differences and similarities between them $[14,15,17]$.

\section{Measurement Setup}

The laboratory setup, which is presented schematically in Figure 1, was used in the measurements. A source of testing voltage was a six-stage Marx generator of a rated voltage of $500 \mathrm{kV}$ and a storage energy of $2.2 \mathrm{~kJ}$. This generator produced a standard positive lightning impulse voltage of $1.2 / 50 \mu \mathrm{s}$. It was supplied by a testing transformer with a ratio of 230:110000 and a solid-state high voltage rectifier. Measurement of the peak value of voltage impulse was achieved using a resistive voltage divider and a peak value meter. The voltage waveform was also observed on the screen of the oscilloscope used in the experimental setup.

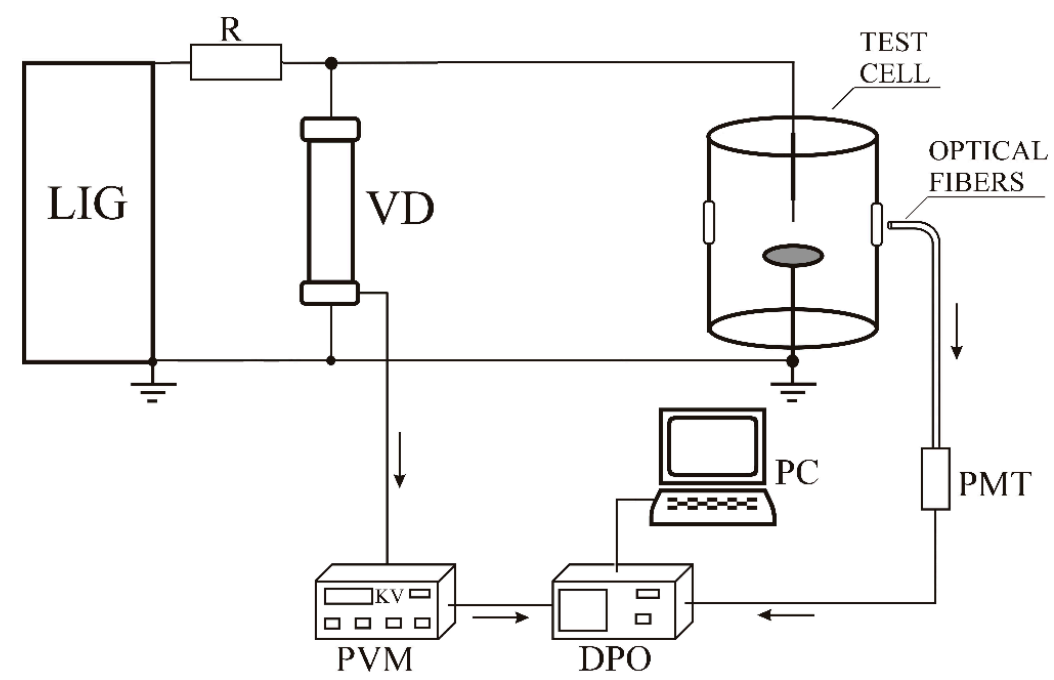

Figure 1. Laboratory setup used in the experiment: LIG—lightning impulse generator, VD—voltage divider, R-limiting resistor, PMT—photomultiplier, DPO—digital oscilloscope, PVM-peak value meter.

The voltage was supplied to the electrode system, which is presented in Figure 2.

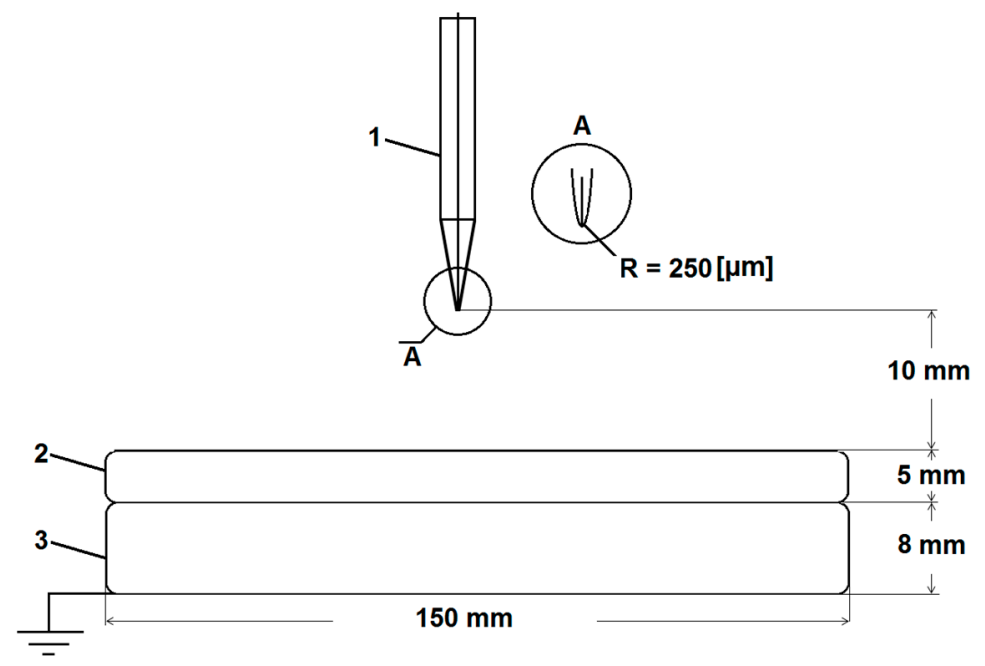

Figure 2. Electrode system used in the studies: $1-\mathrm{HV}$ electrode, 2-insulating pressboard plate, 3-grounded electrode. 
This system was placed in a test cell of 26 liters in volume. It consisted of a HV (high voltage) point electrode made of a tungsten needle with a $250-\mu \mathrm{m}$ radius of curvature and a grounded electrode made of an aluminum plate $150 \mathrm{~mm}$ in diameter. On the surface of the grounded electrode, a 5-mm-thick pressboard plate was deposited. Before the beginning of the experiment, the pressboard plates were dried and impregnated in the liquid, in which the measurements were then performed. The procedure of drying and impregnation included the following:

- $24 \mathrm{~h}$ of drying in a vacuum at a temperature of $105^{\circ} \mathrm{C}$,

- impregnation with the given liquid in a vacuum at a temperature of $85^{\circ} \mathrm{C}$ for $24 \mathrm{~h}$, and

- lying in the vacuum at ambient temperature for $24 \mathrm{~h}$.

The distance between the tip of the HV point and the surface of the insulating pressboard plate was set to $10 \mathrm{~mm}$.

The research was focused on the assessment of the processes that occurred on the basis of the registration of light emitted by the streamers and the breakdown channel using the photomultiplier. It is assumed, in view of the experience gained during many years of studies, that the light pulses are strictly correlated with current pulses providing knowledge about the possible mode of streamer propagation and the level of ionization of streamer channels [13-15,17-19,21,23,24]. The choice of photomultiplier as a light detector resulted from the fact that light generated by the streamers is weak and the amount of light that reaches the side window of the test cell is limited by the absorption and dispersion phenomena, and only a photomultiplier (PMT) is a detector that is sensitive enough to register such a weak light. The light caught by the end of the optical fiber cable placed in the above-mentioned UV (of the lower wavelength range equal to $300 \mathrm{~nm}$ ) side glass window of the test cell was transferred to the photomultiplier. The Hamamatsu R1925 photomultiplier with a wavelength range from 300 to $850 \mathrm{~nm}$ was used. The PMT output signal, after being amplified, was registered using the oscilloscope in the form of a waveform (temporal sequence of discrete negative pulses having the rise-times of a few nanoseconds). Simultaneously, the waveforms obtained were saved on a hard-disk of a PC-type computer where it could be analyzed and compared with other results of the measurements.

\section{Measurement Assumptions}

Three commercial dielectric liquids were used in the experiment: naphtenic type mineral oil, organic synthetic pentaerythritol ester, and natural ester produced from soya bean. All three liquids before the beginning of the experiment were defined in relation to their basic dielectric parameters. This was assumed that the liquids tested had to fulfill the requirements described in the standards corresponding to a given liquid [25-27]. The values of the parameters measured are set in Table 1.

Table 1. Basic dielectric parameters of the liquids tested.

\begin{tabular}{cccc}
\hline Parameters & Synthetic Ester & Natural Ester & Mineral Oil \\
\hline $\begin{array}{c}\text { AC breakdown } \\
\text { voltage-mean value }[\mathrm{kV}]\end{array}$ & 64 & 67 & 66 \\
$\begin{array}{c}\text { Dielectric dissipation factor } \\
\text { at } 90^{\circ} \mathrm{C} \text { and } 50 \mathrm{~Hz}\end{array}$ & 0.0108 & 0.0446 & 0.004 \\
Moisture content $[\mathrm{ppm}]$ & 129 & 102 & 12 \\
\hline
\end{tabular}

The next step was to define a measurement cycle. This cycle was related to previously estimated inception voltages of the streamers. A procedure of inception voltage estimation was described in detail in [28]. The calculations were performed using MOSTAT software where the maximum likelihood method was applied. This software is the authors' tool, which was created at the High Voltage Division of the Institute of Electrical Power Engineering of Lodz University of Technology, Poland, and has been tested from many years, solving both scientific and industry problems $[17,24,29-31]$. The results 
of this estimation for the considered gap distance of $10 \mathrm{~mm}$ are quoted in Table 2. The statistical distribution used for estimation was a three-parameter Weibull distribution described by Equation (1) presented below.

$$
\mathrm{F}(V)=1-\exp \left[-\left(\frac{V_{\mathrm{i}}-V_{0}}{V_{\mathrm{m}}-V_{0}}\right)^{k}\right] .
$$

In this equation,

- $\quad V_{0}$ is the location parameter for which $\mathrm{F}\left(V_{0}\right)=0$, meaning the threshold value of voltage below, in which discharge initiation in a given electrode configuration does not occur (expressed in $\mathrm{kV}$ );

- $V_{\mathrm{m}}$ is the scale parameter for which $\mathrm{F}\left(V_{\mathrm{m}}\right)=1-\mathrm{e}^{-1} \approx 0.632$, representing the value of voltage below, in which $63.2 \%$ of the analyzed population of inception voltages is included (expressed in $\mathrm{kV}$ );

- $\quad k$ is the shape parameter, a measure of the dispersion of the data;

- $V_{\mathrm{i}}$ is the random variable (inception voltages measured in $\mathrm{kV}$ ).

In addition to the main parameters of the Weibull distribution, the 0.5 th percentile (median $V_{\text {Med }}$ ) of the measured values was added.

Table 2. Weibull distribution parameters for positive impulse inception voltages.

\begin{tabular}{ccccc}
\hline Type of Liquid & $\boldsymbol{V}_{\mathbf{0}}[\mathbf{k V}]$ & $\boldsymbol{V}_{\mathbf{m}}[\mathbf{k V}]$ & $\boldsymbol{k}$ & $\boldsymbol{V}_{\mathbf{M e d}}[\mathbf{k V}]$ \\
\hline Synthetic ester & 49.9 & 55.8 & 0.9 & 53.7 \\
Natural ester & 49.3 & 54.4 & 1.6 & 53.4 \\
Mineral oil & 43.2 & 55.3 & 4.2 & 54.3 \\
\hline
\end{tabular}

On the basis of the results obtained, the reference value was determined as the starting value for the studies planned. This value was rounded up for an integer value taking into account the voltage step assumed. Hence, $55 \mathrm{kV}$ was treated as a reference inception voltage $V_{\mathrm{i}}$ for all the liquids tested. This was done because similar values $V_{\text {Med }}$ were obtained in each case. After the inception voltage estimation, it was assumed that, starting from this value of the testing voltage, the next voltage levels would be reached by increasing the voltage in $0.2 V_{\mathrm{i}}$ steps.

For the inception voltage and subsequent inception voltage multipliers, 20 lightning impulses were supplied to the electrode system tested at each voltage level. The oscillograms of light were collected in each case, and the surface of insulating plate placed on the grounded electrode was simultaneously observed after every 5 impulses. Before beginning the experiment, it was assumed that the insulating plate would be changed after each voltage step. However, taking into account that significant changes were observed on the surface of the pressboard as a result of the impact of developing streamers, the plates were changed after every 10 lightning impulses supplied.

\section{Results of the Measurements}

Figure 3 presents the representative oscillograms registered for the reference inception voltage $V_{\mathrm{i}}=55 \mathrm{kV}$. These oscillograms are similar to each other, showing a sequence of discrete light pulses rising in time. This means that the streamers developed step by step, and each step was connected with the next extension of the streamer channels, which occurred one by one with nanosecond intervals. After reaching some distance from the HV point, electrode streamers probably disappeared in the space between the electrodes since the light pulses suddenly ended. Confirmation of this fact was reached by observation of the insulating plates used. There were no traces on the surface of these plates. Thus, the propagation mode observed was assessed as a propagation of the so-called "stopping length" streamers, probably of the second propagation mode. Alternatively, the streamers finished their propagation, reaching the insulating plate placed on the grounded electrode but without the breakdown and without any other similar phenomena. The disappearance of the streamers in the 
electrode space was the result of a low electrical field stress, existing in some distance from the HV point and too weak an impact of space charge that cannot maintain the ionization processes. In all of the liquids tested, this disappearance followed after a few $\mu$ s from the moment of the lightning impulse supplied [13-15,21].

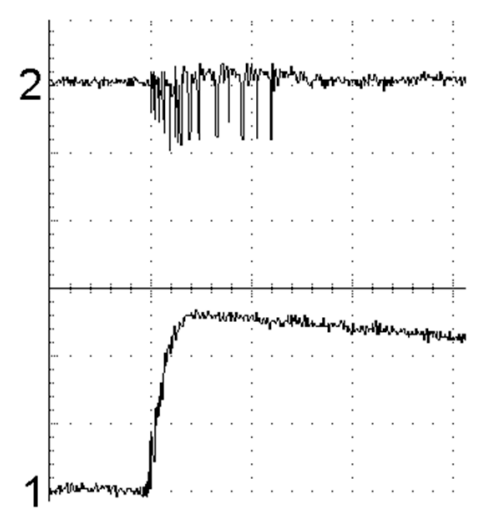

(a)

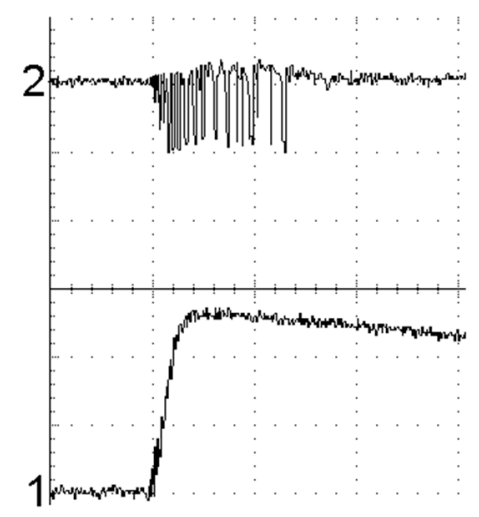

(b)

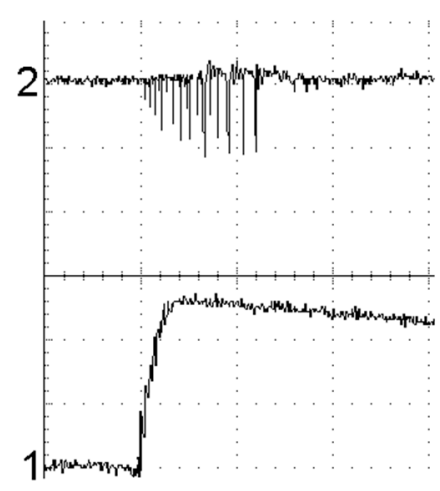

(c)

Figure 3. Oscillograms registered at testing voltage equal to $V_{\mathrm{i}}=55 \mathrm{kV}$ : (a) synthetic ester, (b) natural ester, (c) mineral oil; 1 -voltage [20 kV/div.], 2-light [arb. units], $t=4 \mu \mathrm{s} /$ div.

A comparison of the oscillograms registered for the tested liquids showed significant visible differences of higher frequency of the light pulses registered for streamers developing in esters. Simultaneously, slightly higher peak values of these pulses were observed in such cases. The observed phenomenon may be explained as an easier way for the next step of propagation when the streamers develop in one of the esters. Because such a step represents the extension of the streamer channels resulting from the influence of actual electrical field stress and space charge left by the previous discharge, it may be supposed that re-ignition of the streamers, which requires restoration of the former field stress to the value able to cause the next ionization and excitation processes, for the individual liquids tested occurs in a slightly different way. Re-ignition happens more easily when streamers develop in esters with simultaneous intensification of the ionization processes.

Increase of the testing voltage caused the changes in the oscillograms registered. For all the liquids tested, the sequence of light pulses ended as a wide light pulse saturated the photomultiplier. This took place after 5-6 $\mu \mathrm{s}$ from the moment at which lightning impulse was supplied to the electrode system. Because intense flash finishing streamer propagation was also observed, the wide light pulse from the oscillograms may be identified solely with this flash. The voltage waveform, however, did not indicate a breakdown (voltage collapse was not observed); thus, it may be supposed that the streamers touched the insulating plate placed on the grounded electrode and that surface discharges started to develop with the creation of a return channel, a result of capacitive coupling between the HV point and the grounded plate $[17,24]$. The intensity of the processes connected with streamer propagation was, as in the case of the measurements at inception voltage, higher in the case where one of the esters was the liquid under the test. In such cases, the frequency of light pulses registered was higher, and the width of the pulse finishing the process of streamer propagation was greater. An additional fact in favor of the more intense processes occurring during the development of the streamers in esters was the observation of the insulating pressboard plate after emptying a test cell from the given liquid. The tracks left on the plate used during the measurements in the ester liquids indicated a more intense penetration of the surface of the plate with a simultaneous greater number of channels in comparison with the analogically observed channels formed during the measurements in mineral oil.

Figure 4 presents the representative oscillograms concerning the above-mentioned testing voltage equal to $1.2 V_{\mathrm{i}}(66 \mathrm{kV})$. 


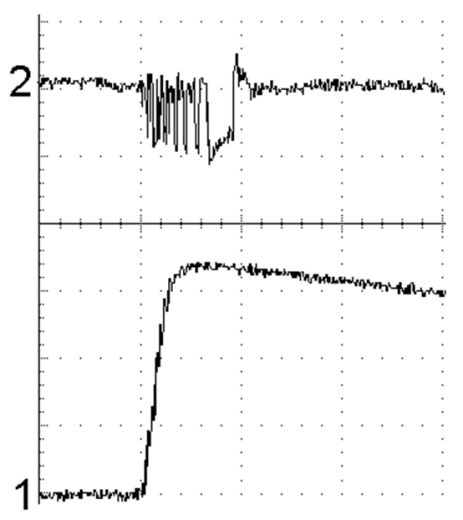

(a)

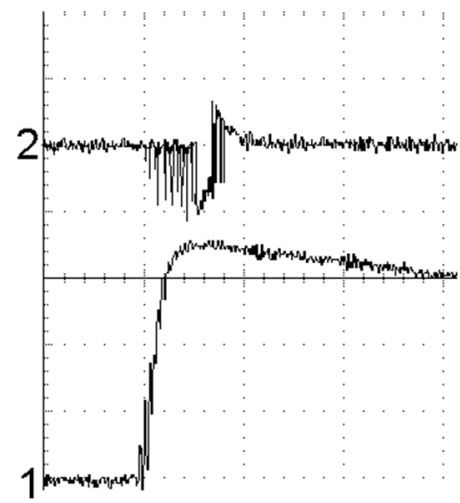

(b)

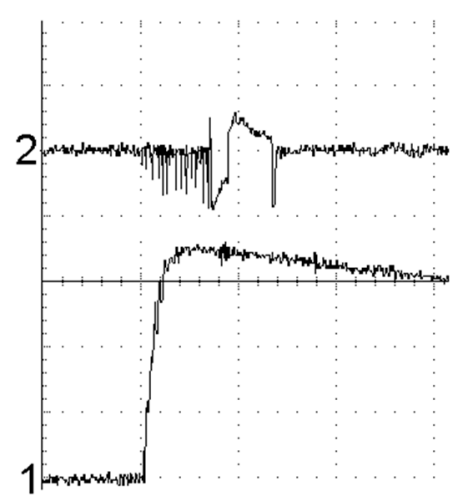

(c)

Figure 4. Oscillograms registered at testing voltage equal to $1.2 V_{\mathrm{i}}=66 \mathrm{kV}$ : (a) synthetic ester, (b) natural ester, (c) mineral oil; 1 -voltage [20 kV/div.], 2-light [arb. units], $t=4 \mu \mathrm{s} / \mathrm{div}$.

The subsequent testing voltages caused many problems during measurements. In all cases at the inception voltage multipliers in the range between 1.4 and $1.8 V_{\mathrm{i}}$, a more intense streamer propagation started to be observed. This was deduced from the fact that a wide light pulse finishing the streamer development appeared after circa $1 \mu \mathrm{s}$, thus at least four times faster than at a voltage equal to $1.2 V_{\mathrm{i}}$. A simple calculation of the propagation velocity considering gap distance and time to appearance of wide light pulse indicated a minimum $10 \mathrm{~mm} / \mu \mathrm{s}$ of propagation velocity, which may allow for the identification of the propagation mode as a propagation of fast streamers in very small gaps [13-15,18-22,24]. The appearance of such a phenomenon in synthetic and natural ester was observed for all the cases concerning the inception voltage multipliers equal to $1.8 V_{\mathrm{i}}$. For the multiplier of $1.4 V_{\mathrm{i}}$, such a situation took place for synthetic ester in 13 of 20 supplied lightning impulses and for natural ester in 14 of 20 impulses. In turn for $1.6 V_{\mathrm{i}}, 18$ of 20 supplied impulses caused fast streamer propagation in the case of the synthetic ester and in all 20 cases when the tested liquid was natural ester. Contrary to the results obtained for ester liquids in the case of mineral oil, only 11 of 20 oscillograms registered at $1.4 V_{\mathrm{i}}$ concerned the propagation of fast streamers, 14 of 20 at voltage level equal to $1.6 V_{\mathrm{i}}$, and all for $1.8 V_{\mathrm{i}}$. In addition, the development of streamers was accompanied in many cases with breakdown, during which the light was emitted more intensely than in the case of the above-mentioned return channel. The breakdown phenomena were visible in the voltage waveforms in the form of a sudden voltage collapse. For 20 lightning impulses at a voltage level equal to $1.4 V_{\mathrm{i}}$, breakdown in synthetic ester took place seven times, in natural ester nine times, but in mineral oil not once. For the testing voltage equal to $1.6 V_{\mathrm{i}}$, breakdown was observed 14 times in synthetic ester and 18 times in natural ester. At $1.8 V_{\mathrm{i}}$, breakdown was, however, identified in all the cases concerning both synthetic and natural ester. In mineral oil, breakdown occurred 6 times at $1.6 V_{\mathrm{i}}$ and 13 times at $1.8 V_{\mathrm{i}}$. This confirmed the assumption that the variety of phenomena in the point-insulating plate electrode system is greater than in the classical experimental electrode system, including only bare electrodes. A summary of the data collected during the measurements is presented collectively in Table 3 and graphically in Figures 5 and 6.

In order to assess whether bridging the electrodes took place along the surface of the insulating plate or with its inclusion, each plate was tested under AC voltage in the parallel electrode system in accordance with Standard IEC 60243 [32]. If the increased AC voltage did not cause the short circuit, it was recognized that breakdown through the plate did not occur. In all of the cases, the tests performed did not indicate a breakdown of the insulating plates used, thus showing a way for an inductive plasma channel that bridges the electrodes followed, as shown in Figure 7, along the surface

of the plate. 
Table 3. Number of fast streamers and number of breakdowns per 20 lightning impulses (LI) supplied to the electrode system tested.

\begin{tabular}{ccccccc}
\hline & \multicolumn{5}{c}{ Liquid Type } \\
\cline { 2 - 6 } $\begin{array}{c}\text { Inception } \\
\text { Voltage } \\
\text { Multiplier }\end{array}$ & \multicolumn{2}{c}{ Synthetic Ester } & \multicolumn{2}{c}{ Natural Ester } \\
\cline { 2 - 6 } & $\begin{array}{c}\text { Number of } \\
\text { Fast Streamers } \\
\text { per 20 LI }\end{array}$ & $\begin{array}{c}\text { Number of } \\
\text { Breakdowns } \\
\text { per 20 LI }\end{array}$ & $\begin{array}{c}\text { Number of } \\
\text { Fast Streamers } \\
\text { per 20 LI }\end{array}$ & $\begin{array}{c}\text { Number of } \\
\text { Breakdowns } \\
\text { per 20 LI }\end{array}$ & $\begin{array}{c}\text { Number of } \\
\text { Fast Streamers } \\
\text { per 20 LI }\end{array}$ & $\begin{array}{c}\text { Number of } \\
\text { Breakdowns } \\
\text { per 20 LI }\end{array}$ \\
& 13 & Supplied & Supplied & Supplied & Supplied & Supplied \\
\hline $1.4 V_{\mathrm{i}}$ & 18 & 7 & 14 & 9 & 11 & 0 \\
$1.6 V_{\mathrm{i}}$ & 20 & 20 & 20 & 18 & 14 & 6 \\
$1.8 V_{\mathrm{i}}$ & 20 & 20 & 20 & 20 & 13 \\
\hline
\end{tabular}

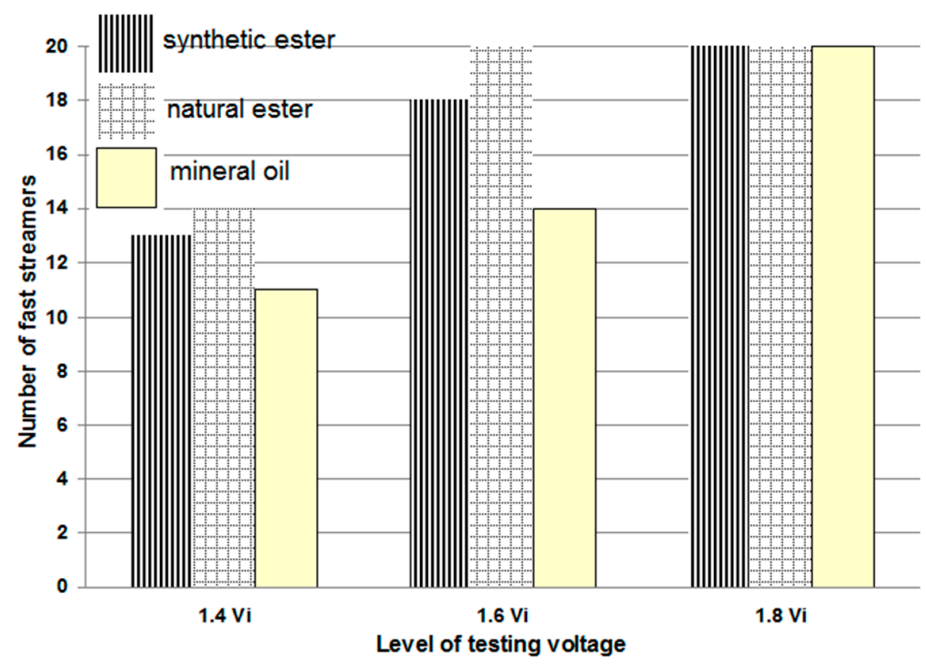

Figure 5. Number of fast streamers per 20 lightning impulses supplied to the electrode setup tested at a given value of testing voltage.

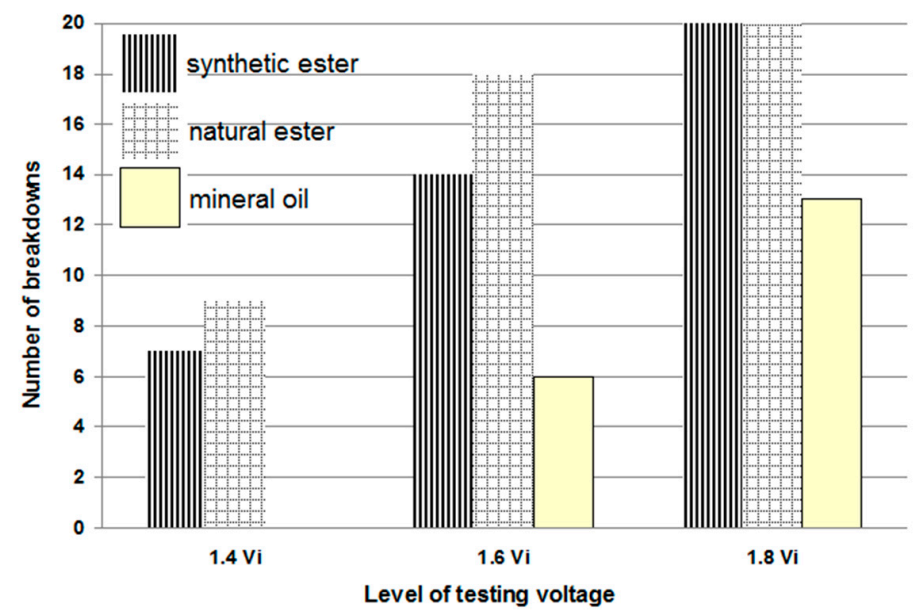

Figure 6. Number of breakdowns per 20 lightning impulses supplied to the electrode setup tested at a given value of testing voltage.

Similar to the case of lower testing voltages, the intensity of the processes connected with the streamers developing in esters was greater, which was confirmed again both on the basis of oscillograms registered and by observation of the pressboard plates after being removed from the test cell. The channels on the plates were again more intense in the case of the ester liquids. 


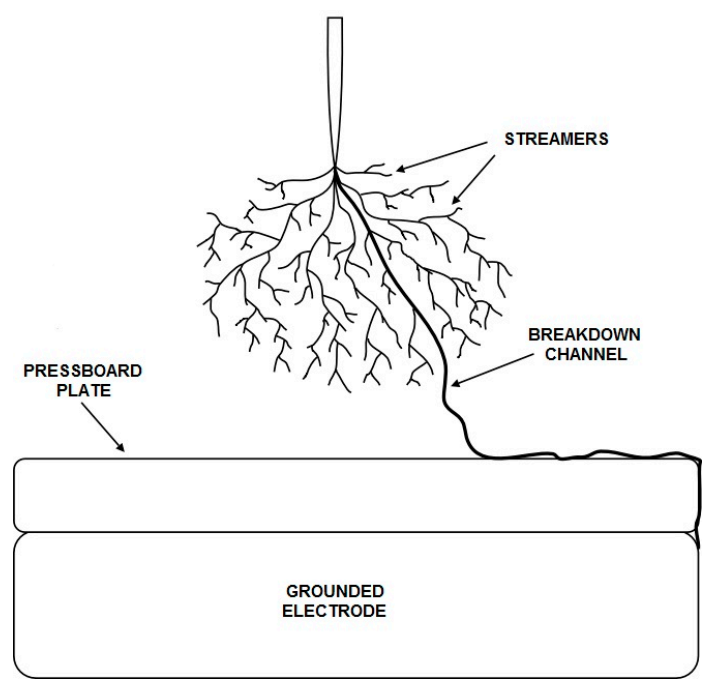

Figure 7. The way of breakdown channel formed.

Figure 8 presents the selected oscillograms concerning the development of fast streamers at a voltage level equal to $1.4 V_{\mathrm{i}}(77 \mathrm{kV})$. Figure 9 shows, however, the oscillograms registered for breakdowns at $1.8 V_{\mathrm{i}}$. For all the liquids tested, breakdown occurred after a time shorter than $1 \mu \mathrm{s}$; thus, the lightning impulse supplied did not achieve its peak value.

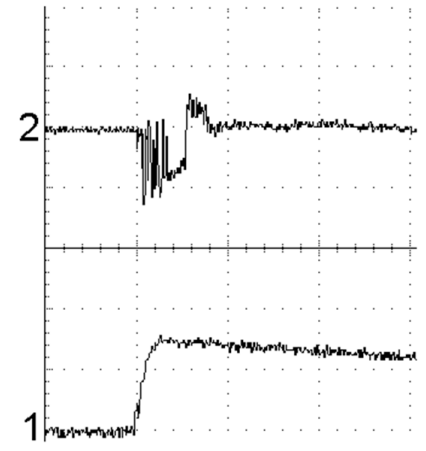

(a)

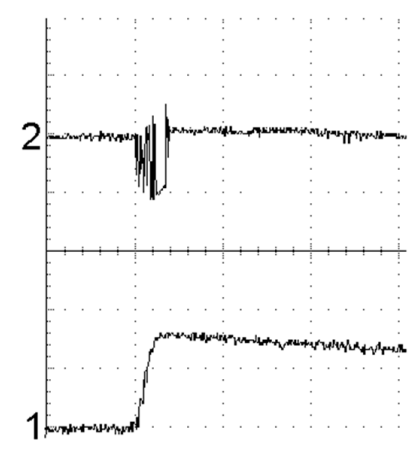

(b)

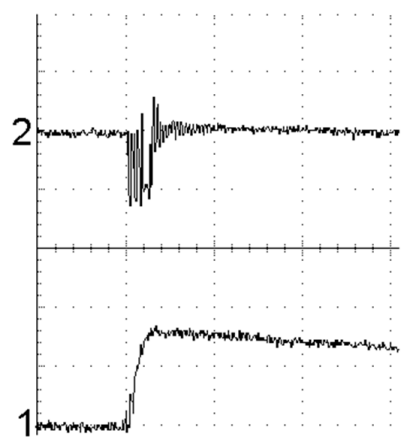

(c)

Figure 8. Oscillograms registered at testing voltage equal to $1.4 V_{\mathrm{i}}=77 \mathrm{kV}$ : (a) synthetic ester, (b) natural ester, (c) mineral oil; 1 -voltage [50 kV/div.], 2-light [arb. units], $t=4 \mu \mathrm{s} / \mathrm{div}$.

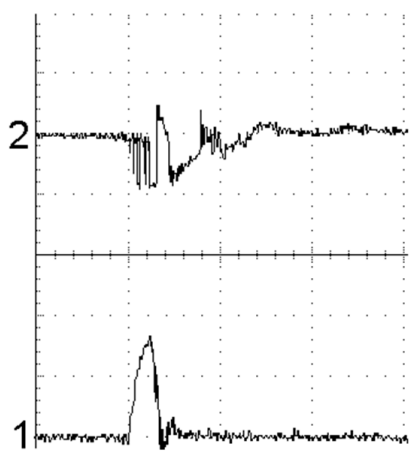

(a)

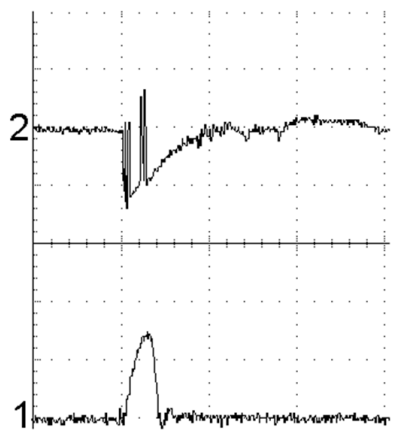

(b)

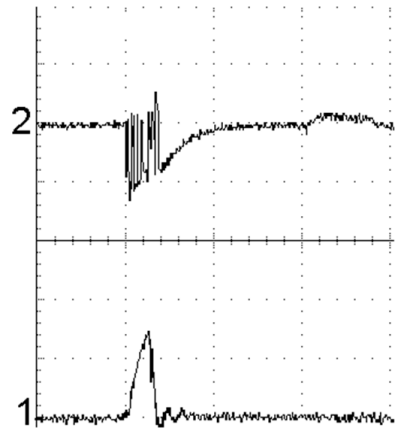

(c)

Figure 9. Oscillograms registered at testing voltage equal to $1.8 V_{\mathrm{i}}=99 \mathrm{kV}$ : (a) synthetic ester, (b) natural ester, (c) mineral oil; 1 -voltage [50 kV/div.], 2-light [arb. units], $t=2 \mu \mathrm{s} /$ div. 
Due to the fact that, at a testing voltage equal to $1.8 V_{\mathrm{i}}$ in synthetic ester and natural ester, breakdown occurred each time and always at the front of the lightning impulse, studies at higher values of voltage ceased. This resulted from the assumption that, with a large probability, such studies would not have brought more valuable information about the comparison of the pre-breakdown and breakdown processes in esters and mineral oil. It is, however, difficult to observe, beyond these differences indicated in the macro scale (number of fast discharges or breakdowns per 20 impulses supplied), any additional aspects in favor of one of the liquids tested when the time of discharge development from the initiation up to breakdown is less than $1 \mu \mathrm{s}$. Simultaneously, seeking the limitation in mineral oil at which, for 20 supplied impulses, 20 breakdowns occur also does not seem to make sense because better properties of the mineral oil have been clearly specified for the lower voltage multipliers on the basis of the studies performed.

\section{Conclusions}

On the basis of the studies performed, the following conclusions can be drawn:

1. In the point-insulating plate electrode systems investigated in these studies, the variety of phenomena which are possible to observe at a given voltage level is greater than that in classically applied electrode systems, including bare electrodes. The unambiguous inference is therefore much more difficult in the considered case.

2. The measurements performed demonstrated that, in the case of the propagation of already-initiated streamers in the tested point-insulating plate electrode system, ester liquids, as in the case of the systems with bare electrodes, demonstrate a lower resistance against the appearance of fast and energetic streamers than mineral oil. Although the inception voltage and the threshold value of the testing voltage for the appearance of fast streamers are similar, for both of the liquids tested, the differences in the results obtained are clearly indicated. The number of fast streamers observed for the voltages between 1.4 and 1.8 of $V_{\mathrm{i}}$ was always much higher in the case of synthetic and natural ester than that of mineral oil.

3. The ability to form a breakdown channel was also higher in the case of the ester liquids, where breakdown occurred almost always, only at the voltage level equal to $1.6 V_{\mathrm{i}}$. For mineral oil, for this voltage level, the different types of streamer propagation modes were registered from slow propagating streamers, through fast streamers that did not lead to the breakdown, up to breakdown similar to this observed in the esters. Intensification of the differences between the liquids tested at testing voltages equal to $1.8 V_{\mathrm{i}}$ definitely strengthened the above-formed conclusion.

4. Limiting the comparison only to the esters tested, it was found that synthetic ester behaved a little better under lightning stresses. Both for 1.4 and $1.6 V_{\mathrm{i}}$, the number of fast streamers registered and the number of breakdowns occurring at the 20 lightning impulses supplied were lower than the corresponding numbers concerning natural ester. However, comparing the oscillograms collected, there were no obvious differences between the esters under consideration.

5. Relating the observations quoted to the theory of propagation of the streamers in liquid dielectrics, it may be supposed that both esters in small point-insulating plate electrode systems are similarly more susceptible on the appearance of such types of the streamers, which propagate as a result of liquid phase ionization (3rd or 4th propagation mode). The channels of such streamers seem to be more energetic than channels of the streamers propagating slowly (2nd mode). In turn, if the breakdown occurs in the gap that is filled with one of the esters, it is characterized by a more intense impact on solid insulation that may be damaged easier.

Acknowledgments: The studies presented in this article were supported in part by the Polish National Science Centre under Grant ST8/03549 and within statutory works realized in Institute of Electrical Power Engineering at Faculty of Electrical, Electronic, Computer and Control Engineering of Lodz University of Technology. 
Author Contributions: The research presented in this paper is a result of the sole effort of the author Pawel Rozga who prepared the assumption for the studies, performed the studies, analyzed their results, and formed the final conclusions.

Conflicts of Interest: The author declares no conflict of interest.

\section{References}

1. McShane, C.P. Vegetable-oil-based dielectric coolants. IEEE Ind. Appl. Mag. 2002, 2, 34-41. [CrossRef]

2. Borsi, H.; Gockenbach, E. Properties of ester liquid Midel 7131 as an alternative liquid to mineral oil for transformers. IEEE Int. Conf. Dielectr. Liq. 2005, 377-380. [CrossRef]

3. Gockenbach, E.; Borsi, H. Natural and synthetic ester liquids as alternative to mineral oil for power transformers. IEEE Conf. Electr. Insul. Dielectr. Phenom. 2008, 521-524. [CrossRef]

4. Perrier, C.; Beroual, A. Experimental investigations on insulating liquids for power transformers: Mineral, ester and silicone oils. IEEE Elect. Insul. Mag. 2009, 25, 6-13. [CrossRef]

5. CIGRE brochure 436. Experiences in Service with New Insulating Liquids; International Council on Large Electric Systems: Paris, France, 2011.

6. Lashbrook, M.; Kuhn, M. The use of ester transformer fluids for increased fire safety and reduced costs. CIGRE Tech. Progr. 2012, A2-A210.

7. Fernández, I.; Ortiz, A.; Delgado, F.; Renedo, C.; Pérez, S. Comparative evaluation of alternative fluids for power transformers. Electr. Power Syst. Res. 2013, 98, 58-69. [CrossRef]

8. Liao, R.J.; Hao, J.; Chen, G.; Ma, Z.Q.; Yang, L.J. A comparative study of physicochemical, dielectric and thermal properties of pressboard insulation impregnated with natural ester and mineral oil. IEEE Trans. Dielectr. Electr. Insul. 2011, 18, 1626-1637. [CrossRef]

9. Martins, M.A.G.; Gomes, A.R. Comparative study of the thermal degradation of synthetic and natural esters and mineral oil: effect of oil type in the thermal degradation of insulating Kraft paper. IEEE Electr. Insul. Mag. 2012, 28, 22-28. [CrossRef]

10. Talhi, M.; Fofana, I.; Flazi, S. Comparative study of the electrostatic charging tendency between synthetic ester and mineral oil. IEEE Trans. Dielectr. Electr. Insul. 2013, 20, 1598-1606. [CrossRef]

11. Loiselle, L.; Fofana, I.; Sabau, J.; Magdaleno-Adame, S.; Olivares-Galvan, J.C. Comparative studies of the stability of various fluids under electrical discharge and thermal stresses. IEEE Trans. Dielectr. Electr. Insul. 2015, 22, 2491-2499. [CrossRef]

12. Bandara, K.; Ekanayake, C.; Saha, T.; Ma, H. Performance of natural ester as a transformer oil in moisture-rich environments. Energies 2016, 9, 258. [CrossRef]

13. Duy, C.T.; Denat, A.; Lesaint, O.; Bonifaci, N. Streamer propagation and breakdown in natural ester at high voltage. IEEE Trans. Dielectr. Electr. Insul. 2009, 16, 1582-1594. [CrossRef]

14. Dang, V-H.; Beroual, A.; Perrier, C. Comparative study of streamer phenomena in mineral, synthetic and natural ester oils under lightning impulse voltage. Int. Conf. High Volt. Eng. Appl. 2010, 560-563. [CrossRef]

15. Liu, Q.; Wang, Z.D. Streamer characteristic and breakdown in synthetic and natural ester transformer liquids under standard lightning impulse. IEEE Trans. Dielectr. Electr. Insul. 2011, 18, 285-294. [CrossRef]

16. Liu, Q.; Wang, Z.D. Secondary reverse streamer observed in an ester insulating liquid under negative impulse voltage. J. Phys. D: Appl. Phys. 2011, 44. [CrossRef]

17. Rozga, P. Streamer propagation in small gaps of synthetic ester and mineral oil under lightning impulse. IEEE Trans. Dielectr. Electr. Insul. 2015, 22, 2754-2762. [CrossRef]

18. Devins, J.C.; Rzad, S.J.; Schwabe, R.J. Breakdown and prebreakdown phenomena in liquids. J. Appl. Phys. 1981, 52, 4531-4545. [CrossRef]

19. Beroual, A. Electronic and gaseous processes in prebreakdown phenomena of dielectric liquids. J. Appl. Phys. 1993, 73, 4528-4532. [CrossRef]

20. Tobazoen, R. Prebreakdown phenomena in dielectric liquids. IEEE Trans. Dielectr. Electr. Insul. 1996, 1, 1132-1147. [CrossRef]

21. Lesaint, O.; Massala, G. Positive streamer propagation in large oil gaps: Experimental characterization of propagation mode. IEEE Trans. Dielectr. Electr. Insul. 1998, 5, 360-370. [CrossRef]

22. Galczak, J. Electrical discharges in mineral oil developing from insulated transformer wire to plane. Arch. Electr. Eng. 2004, 73, 353-367. 
23. Lundgaard, L.; Linhjell, D.; Berg, G.; Sigmond, S. Propagation of positive and negative streamers in oil with and without pressboard interfaces. IEEE Trans. Dielectr. Electr. Insul. 1998, 5, 388-395. [CrossRef]

24. Rozga, P. The influence of paper insulation on the prebreakdown phenomena in mineral oil under lightning impulse. IEEE Trans. Dielectr. Electr. Insul. 2011, 11, 720-727. [CrossRef]

25. IEC 60296 Standard: Fluids for Electrotechnical Applications-Unused Mineral Insulating Oils for Transformers and Switchgears; International Electrotechnical Commission: Geneva, Switzerland, 2012.

26. IEC 61099 Standard: Insulating liquids - Specifications for Unused Synthetic Organic Esters for Electrical Purposes; International Electrotechnical Commission: Geneva, Switzerland, 2011.

27. IEC 62770 Standard: Fluids for Electrotechnical Applications - Unused Natural Esters for Transformers and Similar Electrical Equipment; International Electrotechnical Commission: Geneva, Switzerland, 2014.

28. Rozga, P.; Stanek, M.; Cieslinski, D. Comparison of properties of electrical discharges developing in natural and synthetic ester at inception voltage. 2013 IEEE Annual Report Conf. Electr. Insul. Diel. Phenom. 2013, 891-894. [CrossRef]

29. Mosinski, F.; Wodzinski, J.; Sikorski, L.; Ziencikiewicz, J. Electrical strength of paper-oil insulation subjected to composite voltages. IEEE Trans. Dielectr. Electr. Insul. 1994, 1, 615-623. [CrossRef]

30. Mosinski, F.; Piotrowski, T. New statistical methods for evaluation of DGA data. IEEE Trans. Dielectr. Electr. Insul. 2003, 10, 260-265. [CrossRef]

31. Piotrowski, T. Probability distribution of gases dissolved in oil of failed power transformers. Int. Conf. High Volt. Eng. Applic. 2014, 1-4. [CrossRef]

32. IEC 60243-1 Standard: Electric Strength of Insulating Materials - Test Methods - Part 1: Tests at Power Frequencies; International Electrotechnical Commission: Geneva, Switzerland, 2013.

(C) 2016 by the author; licensee MDPI, Basel, Switzerland. This article is an open access article distributed under the terms and conditions of the Creative Commons Attribution (CC-BY) license (http:// creativecommons.org/licenses/by/4.0/). 